\title{
Multifactorial assessment and targeted intervention to reduce falls among the oldest-old: a randomized controlled trial
}

\author{
Assumpta Ferrer' \\ Francesc Formiga ${ }^{2,3}$ \\ Héctor Sanz ${ }^{4}$ \\ Oscar J de Vries ${ }^{5}$ \\ Teresa Badia ${ }^{6}$ \\ Ramón Pujol ${ }^{2,3}$

\section{On behalf of the} \\ OCTABAIX Study Group
}

'Primary Healthcare Centre "EI Plà" CAP-I, Sant Feliu de Llobregat, ${ }^{2}$ Geriatric Unit, Internal Medicine Service, Hospital Universitari de Bellvitge, ${ }^{3}$ Bellvitge Biomedical Research Institute, IDIBELL, L'Hospitalet de Llobregat, ${ }^{4}$ Support Research Unit, Primary Health Department Costa Ponent, IDIAP Jordi Gol, Barcelona, Spain; ${ }^{5}$ Department of Internal Medicine, VU University Medical Center, Amsterdam, the Netherlands; ${ }^{6}$ Primary Healthcare Centre Martorell, Barcelona, Spain
Correspondence: Assumpta Ferrer Feliu CAP- El Plà PI Felip Alcantara s/n 08980, St Feliu de Llobregat, Barcelona, Spain Tel +34936852888

Fax+34932607420

Email aferrer.cp.ics@gencat.cat
This article was published in the following Dove Press journal:

Clinical Interventions in Aging

25 February 2014

Number of times this article has been viewed

Background: The purpose of this study was to assess the effectiveness of a multifactorial intervention to reduce falls among the oldest-old people, including individuals with cognitive impairment or comorbidities.

Methods: A randomized, single-blind, parallel-group clinical trial was conducted from January 2009 to December 2010 in seven primary health care centers in Baix Llobregat (Barcelona). Of 696 referred people who were born in 1924, 328 were randomized to an intervention group or a control group. The intervention model used an algorithm and was multifaceted for both patients and their primary care providers. Primary outcomes were risk of falling and time until falls. Data analyses were by intention-to-treat.

Results: Sixty-five (39.6\%) subjects in the intervention group and 48 (29.3\%) in the control group fell during follow-up. The difference in the risk of falls was not significant (relative risk $1.28,95 \%$ confidence interval [CI] 0.94-1.75). Cox regression models with time from randomization to the first fall were not significant. Cox models for recurrent falls showed that intervention had a negative effect (hazard ratio [HR] 1.46, 95\% CI 1.03-2.09) and that functional impairment (HR 1.42, 95\% CI 0.97-2.12), previous falls (HR 1.09, 95\% CI 0.74-1.60), and cognitive impairment (HR 1.08, 95\% CI 0.72-1.60) had no effect on the assessment.

Conclusion: This multifactorial intervention among octogenarians, including individuals with cognitive impairment or comorbidities, did not result in a reduction in falls. A history of previous falls, disability, and cognitive impairment had no effect on the program among the community-dwelling subjects in this study.

Keywords: elderly, falls, intervention

\section{Introduction}

In recent decades, the oldest-old segment of the population has been the most rapidly expanding, and is expected to reach $10 \%$ in developed countries by $2050 .{ }^{1}$ Approximately one third of the population aged over 65 years and one half of nonagenarians experience at least one fall each year, and 15\% fall at least twice. Therefore, falls are a major health problem, especially in the oldest-old group and the consequences of falling are severe. ${ }^{2,3}$ Nearly $10 \%$ of falls result in a fracture and the mortality index with a fracture increases $33 \%$.,5

The evidence from randomized trials suggests that there are a number of fall prevention interventions with proven effectiveness. ${ }^{6-9}$ However, most studies have specifically excluded the oldest-old age group, older people who are cognitively impaired, and those with comorbidities. ${ }^{6,7}$ Therefore, the results of these studies may not be generalizable to this important group of elderly people at risk. However, two studies do 
exist on the oldest group of people in our community, ie, the Stepping On study that involved community-dwelling veteran subjects ${ }^{10}$ and the home-based study on rural community-dwelling nonagenarians, which found that intervention was effective. ${ }^{11}$ Another study of cognitively impaired older people included an intervention that was fully organized and coordinated by a hospital-based research team, which made adherence difficult. The results showed that this intervention was not effective. ${ }^{12} \mathrm{~A}$ trial that did not exclude cognitively impaired participants and aimed to improve vision in individuals with a mean age of 81 years may even have increased the risk of falls. ${ }^{13}$ These facts emphasize the need to know which group of oldest people are the most suitable for assessment. Moreover, various clinical practice guidelines ${ }^{14,15}$ and recent prevention programs recommend multifactorial intervention as a primary treatment strategy. ${ }^{8,16,17}$ However, none of these assessments contain high-level evidence on all community-dwelling older persons, including those with cognitive impairment. ${ }^{18}$

The aim of this study was to evaluate the effectiveness of a multifactorial assessment and targeted intervention to reduce falls among the oldest-old community-dwelling persons, including those with cognitive impairment and comorbidities.

\section{Materials and methods}

This was a randomized, parallel-group clinical trial (registration number NCT01141166) ${ }^{19}$ conducted between January 2009 and December 2010. The design of the study has been published in detail elsewhere. ${ }^{20}$ All communitydwelling individuals born in 1924 and registered at one of seven primary health care centers in Baix Llobregat, Barcelona, were contacted. The combined population served by these health care teams includes approximately 210,000 individuals from a total of 800,000 inhabitants of the Baix Llobregat area (where $17 \%$ of people are older than 65 years). The seven voluntary health care centers involved in other elderly assessments were from the same geographical area and have similar data with regard to proportion of immigrants (11\%) and population served (70\%). We did not use exclusion criteria for disease or cognitive impairment. The only exclusion criterion was being institutionalized. We selected an age of 85 years as that being very close to the maximum life span in developed countries and therefore representative of the oldest-old group (80 years or older). The institutional ethics committee of Jordi Gol Institute for Primary Care Research approved the study. Research assistants contacted potential participants, and individuals with no exclusion criteria were asked to participate. All subjects who agreed to participate signed their informed consent before the study started. Persons who were unable to give informed consent were included if they had a relative or caregiver who could complete the assessment. There were no differences between respondents and nonresponders in terms of sex, health care center attended, or physician in charge. Data on the subjects were gathered by a health care professional (doctor, nurse, or member of health center), during the first year (baseline), and at 12 and 24 months of follow-up.

The baseline assessment included sociodemographic data (sex, marital status, studies, place of residence), functional status measured by the Barthel Index, ${ }^{21}$ gait by the Tinetti test, ${ }^{22}$ cognitive function measured by the Spanish version of the Mini-Mental State Examination, ${ }^{23}$ nutritional status assessed using the Mini-Nutritional Assessment, ${ }^{24}$ global comorbidity measured using the Charlson Comorbidity Index, ${ }^{25}$ and chronic conditions (hypertension, diabetes mellitus, dyslipidemia, ischemic cardiomyopathy, heart failure, stroke, dementia, anemia, Parkinson's disease, and atrial fibrillation). The number of falls (defined as unexpected events in which an individual came to rest on the ground, floor, or a lower level), ${ }^{9}$ fractures, and hospitalizations in the previous year were recorded, along with the number of long-term drug prescriptions. A health assistant undertook the baseline assessment for all subjects (an informant interview was conducted when the elder was unable to participate fully due to compromised health and/or cognitive ability), according to medical records and interviews in the primary care service or at home for subjects who were not ambulatory. The health care professional provided each subject with a monthly calendar similar to that used in other fall studies ${ }^{5}$ for self-reporting of falls, fractures, and hospitalizations. A blood sample was collected from each participant after the baseline interview and 24 months later. After the baseline questionnaire had been administered, the subjects were randomized to an intervention or control group using a computer-generated randomization table. In total, 696 community-dwelling individuals registered at the seven primary health care centers were born in 1924 . Of these, 142 did not meet the inclusion criteria and 67 died before they were contacted. Of the 487 eligible subjects, $328(67.4 \%)$ were randomized (Figure 1).

\section{Intervention group}

Subjects in the intervention group were assessed for their risk of falling and a treatment plan was devised based on their existing medical care and service networks in the community. 


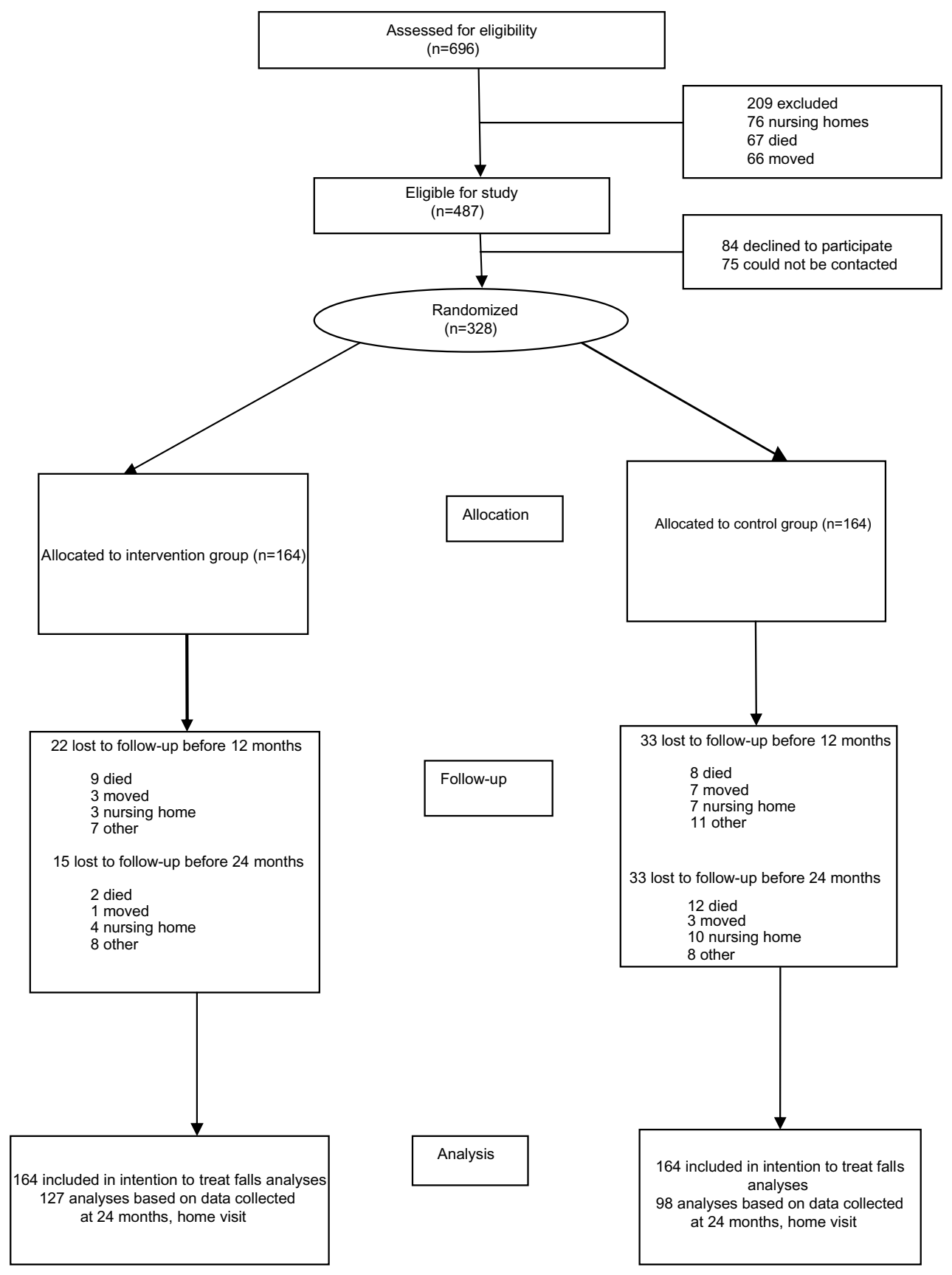

Figure I Flow chart of participants throughout the trial.

The intervention used a specific algorithm that identified nine areas of potentially modifiable risk factors for falls, including psychotropic and cardiovascular drug use, auditory acuity, visual acuity, balance and gait disorders, risk of malnutrition, disability, cognitive impairment, social risk, and home safety (see Supplementary Table 1). A health care professional (doctor or nurse from the health center with specialized training in geriatrics) visited participants in the intervention group after their baseline interview to give recommendations according to the algorithm. For cognitively impaired participants, caregivers were required to be an integral part of the program and ensure that the intervention was implemented. Participants were advised to contact their primary physician to review the results, recommendations, and referrals. Each participant's family physician was mailed after the examination to discuss referrals to medical specialists, changes in medication, and follow-up. Participants in the control group received usual health care.

The algorithm evaluated long-term prescriptions, with special emphasis on significant polypharmacy (five or more 
prescriptions), progressive discontinuation of benzodiazepines, and nutritional or vitamin supplementation. Subjects were referred to an ophthalmologist if their worst corrected monocular near vision was less than $0.5 / 1$ decimals on the Jaeger chart. If there was visual field impairment, the patient was advised to alter their lighting at home to improve visibility (high ambient light level, conventional wall-plug night light). Participants with gait disorders were referred to physical therapists for assessment and balance and strength training. There was a focus on progressive balance exercises over 3 months. Information given was reinforced with printed sheets of standard exercises adapted to this age group. The algorithm also generated recommendations for treatment of auditory impairment when the participant was unable to hear a whispered voice at approximately $0.6 \mathrm{~m}$, for risk of malnutrition, and for functional or cognitive decline when deemed necessary. During the second year, two specific interventions were also offered as another set of recommendations, ie, rehabilitation and nutritional assessment. Rehabilitation assessment included subjects with one or more falls and no or minor cognitive impairment (Mini-Mental State Examination $>19 / 35$ ). These subjects received four 90-minute sessions with a physiotherapist over the course of 6 months coordinated by a specialist in rehabilitation at the referral hospital. Subjects at nutritional risk (Mini-Nutritional Assessment score $\leq 23.5 / 30$ ) had three individual one-hour sessions with a dietician from the referral hospital, who developed plans for individualized nutrition. The nutritionist monitored nutritional intervention at the health care center at 3,6 , and 12 months. At the end of each session, the participants received printed information for use at home.

\section{Follow-up}

The primary outcomes in the control and intervention groups were risk of falling (number of fallers) and time to first and second incident falls after entry into the study. Secondary outcomes were the number of adverse events (fractures, hospitalization) or the start of home care. Falls were ascertained during the annual assessment by self-report on the monthly calendar and from medical records. The health care professional telephoned participants at 3-monthly intervals to collect information from the calendar. To ensure blinding during data collection, measurements done by telephone were delegated to independent assessors at each center who were unaware of group allocation. Secondary outcomes were captured in a manner similar to that used for the primary outcome. Participants who were unavailable for follow-up or who had died were censored at the time of dropping out and were included as censored information in the analysis. The health care professional conducted the 24-month follow-up assessment. In the event of loss to follow-up because of death, the date of death was documented. Adherence to recommendations was monitored by quarterly visits or telephone calls made by the therapist during the first and second years. A recommendation made by the health care professional was considered as adhered to if the participant completed at least $70 \%$ of the session's program at any time in the 24-month period.

\section{Statistical analysis}

The primary outcome of falls was analyzed as the risk of falling (number of fallers) and the time to first, second, and recurrent falls. The study sample is described in more detail elsewhere. ${ }^{20}$ Three statistical methods were used for the primary analysis of falls: relative risk and 95\% confidence interval to compare the number of intervention and control participants with one or more falls during the first and second years of follow-up; a Kaplan-Meier method and log-rank test to compare differences between the intervention and control groups for time to first and second fall; and Cox proportional models, with time from randomization to first fall and the same variables to assess recurrent falls (the first two falls). The hazard ratio of intervention was estimated in the crude model. Intervention, history of previous falls, disability, sex, impaired cognition, and Charlson Comorbidity Index were included in the adjusted model. Secondary outcomes were analyzed as continuous variables by assessing differences between the control group and intervention group at 24 months of follow-up. All analyses were carried out by intention-totreat. Proportional hazards assumption were tested in all models using scaled Schoenfeld residuals and $\log (-\log )$ transformation in Kaplan-Meier curves. Negative binomial models were adjusted with intervention and control group variables stratified by follow-up period in order to estimate incidence rates. Sample characteristics of participants who dropped out versus those who completed follow-up in the first and second year were tested for consistency. The statistical significance level was set at 0.05. All analyses were performed using $\mathrm{R}$ version 2.14.2 software ( $\mathrm{R}$ Foundation for Statistical Computing, Vienna, Austria).

\section{Results}

In total, 328 subjects (including 202 [61.6\%] women) were randomized into this study. The baseline characteristics of the two study groups were similar (Table 1), although subjects in the control group reported more barriers $(P=0.03)$ 
Table I Baseline characteristics of study subjects

\begin{tabular}{|c|c|c|c|}
\hline Characteristics & $\begin{array}{l}\text { Control } \\
(n=164)\end{array}$ & $\begin{array}{l}\text { Intervention } \\
(n=164)\end{array}$ & $P$-value \\
\hline Sex: female, n (\%) & $101(61.6 \%)$ & $101(61.6 \%)$ & 0.91 \\
\hline Widowed marital status, n (\%) & $85(51.8 \%)$ & 89 (54.3\%) & 0.38 \\
\hline Formal education $>6$ years, $n(\%)$ & 31 (18.9\%) & 31 (18.9\%) & 0.83 \\
\hline Lives alone & $50(30.5 \%)$ & $50(30.5 \%)$ & 0.91 \\
\hline Home hazards & 94 (57.3\%) & $114(69.5 \%)$ & 0.03 \\
\hline Visual acuity, median (IQR) & $5.00(3.0-10.0)$ & $5.00(3.0-10.0)$ & 0.33 \\
\hline Impaired auditory acuity, n (\%) & $58(35.4 \%)$ & $66(40.2 \%)$ & 0.42 \\
\hline Hypertension, n (\%) & $128(78.0 \%)$ & $121(73.8 \%)$ & 0.44 \\
\hline Diabetes mellitus, $\mathrm{n}(\%)$ & $26(15.9 \%)$ & $30(18.3 \%)$ & 0.66 \\
\hline Dyslipidemia, n (\%) & $84(51.2 \%)$ & $84(51.2 \%)$ & 0.91 \\
\hline Ischemic cardiomyopathy, n (\%) & $6(3.7 \%)$ & $14(8.5 \%)$ & 0.11 \\
\hline Heart failure, n (\%) & $2 \mid(12.8 \%)$ & $21(12.8 \%)$ & 0.87 \\
\hline Previous stroke, n (\%) & $19(11.6 \%)$ & $30(18.3 \%)$ & 0.12 \\
\hline Dementia, n (\%) & $17(10.4 \%)$ & $14(8.5 \%)$ & 0.71 \\
\hline Anemia, n (\%) & $36(22.0 \%)$ & $20(12.2 \%)$ & 0.03 \\
\hline Parkinson's disease, $\mathrm{n}(\%)$ & $8(4.9 \%)$ & $5(3.1 \%)$ & 0.57 \\
\hline Atrial fibrillation, $\mathrm{n}(\%)$ & $22(13.4 \%)$ & $19(11.6 \%)$ & 0.74 \\
\hline Charlson Comorbidity Index (0-37), median (IQR) & $1.00(0.0-2.0)$ & $1.00(0.0-2.0)$ & 0.55 \\
\hline Number of drugs taken, median (IQR) & $6.00(4.0-8.0)$ & $6.00(4.0-8.0)$ & 0.50 \\
\hline MNA, median (IQR) & $25.0(22.5-27.5)$ & $25.5(23.0-27.5)$ & 0.33 \\
\hline Barthel Index", median (IQR) & $95.0(80.0-100)$ & $95.0(85.0-100)$ & 0.50 \\
\hline Tinetti test (0-9), median (IQR)* & $8.00(5.00-9.00)$ & $8.00(5.00-9.00)$ & 0.56 \\
\hline MEC** median (IQR) & $28.0(22.0-31.0)$ & $29.0(23.8-32.0)$ & 0.16 \\
\hline Falls in previous year, $\mathrm{n}(\%)$ & & & 0.47 \\
\hline 0 & $120(73.2 \%)$ & 115 (70.1\%) & \\
\hline I & $32(19.5 \%)$ & $36(22.0 \%)$ & \\
\hline 2 & $9(5.5 \%)$ & $6(3.7 \%)$ & \\
\hline$\geq 3$ & $3(1.8 \%)$ & $7(4.3 \%)$ & \\
\hline $\mathrm{HbA}_{\mathrm{Ic}}(\%)$, median (IQR) & $5.65(4.9-6.7)$ & $6.05(5.2-7.0)$ & 0.24 \\
\hline Total cholesterol (mmol/L), mean (SD) & $5.02(1.0)$ & $5.04(1.0)$ & 0.88 \\
\hline HDL-c (mmol/L), mean (SD) & $1.47(0.4)$ & $1.45(0.4)$ & 0.66 \\
\hline Albumin $(g / L)$, mean $(S D)^{\pi \pi}$ & $41.2(3.9)$ & $4 I .5(3.8)$ & 0.55 \\
\hline Calcium (mmol/L), mean (SD) $)^{\text {Пाтा }}$ & $2.32(0.1)$ & $2.31(0.1)$ & 0.32 \\
\hline Home care, $\mathrm{n}(\%)$ & $2 \mathrm{I}(12.8 \%)$ & $18(11.1 \%)$ & 0.76 \\
\hline Follow-up (days), median (IQR) & $744(649-77 I)$ & $752(706-774)$ & 0.11 \\
\hline
\end{tabular}

Notes: *Impaired Jaeger score <5; **MEC: Spanish version of the Mini-Mental State Examination (cognitive impairment ,24/35); "Barthel Index, functional status (dependency

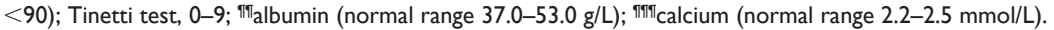

Abbreviations: IQR, interquartile range; SD, standard deviation; MNA, Mini Nutritional Assessment questionnaire (nutritional risk <23.5); HbA ${ }_{I C}$, glucose hemoglobin; HDL-c, high-density lipoprotein cholesterol.

and had more anemia $(P=0.03)$. The history of falls in the previous 12 months was similar between the groups, with $26.8 \%$ of subjects in the control group and $29.9 \%$ in the intervention group $(P=0.47)$ reporting at least one fall during the previous year. There was no difference between the intervention and control groups with regard to number of days of follow-up ( $P=0.11)$. One hundred and three subjects were lost to follow-up. No statistically significant differences were found comparing the sample characteristics of participants who dropped out and those who completed follow-up in the first and second years.

"The completeness of the falls data showed that 275 subjects (including two subjects until they left the study before 12 months) reported any fall during the first year and 238 subjects (fall data were collected for 13 subjects until they left the study from 12-24 months) during the second year."

After one year of follow-up, there had been 62 falls in the control group and 57 falls in the intervention group; during the second year, the numbers of falls were 36 and 96 , respectively. Forty-eight (29.3\%) subjects in the control group and $65(39.6 \%)$ in the intervention group reported one or more falls by the end of follow-up. The relative risk of having had any fall at 24 months of follow-up was increased (but not significantly so, relative risk 1.28, 95\% confidence interval [CI] 0.94-1.75). Similarly, during 
2 years of follow-up in this study, the Kaplan-Meier method revealed no significant differences between intervention and control participants in time to first $(P=0.138)$ and second fall $(P=0.062)$, as shown in Figure 2. In the Cox regression models for the first fall, the results were not significant for any of the variables in the final model (Table 2). In the analyses for recurrent falls, intervention had a significant negative effect (hazards ratio 1.46, 95\% CI 1.03-2.09) in the third model. The intervention group showed no statistically significant difference in the crude first model (hazards ratio 1.42 , 95\% CI 1.00-2.02).

Analyses of secondary outcomes (Table 3 ) did not identify significant longitudinal changes in hospital emergencies or use of home care. However, a significant difference was found in number of fractures, and Table 4 shows the incidence rates (IR) for the intervention group. There was no statistically significant difference in fall rates between the two groups in the 12-month follow-up period, but there were differences during the 12-24-month period (IR 2.06, 95\% CI 1.22-3.5). Adherence to recommendations in the first and second years is shown in Table 5. The 164 intervention participants received a total of 711 recommendations during the first year and 652 during the second year. Of these,
425 recommendations were adhered to in the first year and 522 in the second year.

\section{Discussion}

Strategies to reduce falls in the elderly have been found to be effective. ${ }^{7}$ This was a randomized community care study on reducing falls in the oldest-old people with comorbidity, and included individuals with poor health status. Some studies have used inclusion criteria such as very old age ${ }^{13,26}$ or poor health status (dementia, anemia, heart failure), ${ }^{13,14,27}$ but none combined all of these criteria. Our study found no evidence of reduction in risk of falls in the intervention group. There may be several reasons for this, awareness of which could help in the implementation of alternative strategies in the future.

The first explanation is that this intervention may not have been sufficient to improve muscle weakness or balance in this age group, although adherence with physical therapy was high (74\%) in the current study. These findings are in contrast with the effective intervention results described previously in younger elders ${ }^{28-30}$ and are in accordance with other clinical trials that included subjects of a similar age. ${ }^{31-34}$ Although it is difficult to identify the effect of a particular component in this type of multifactorial intervention, one

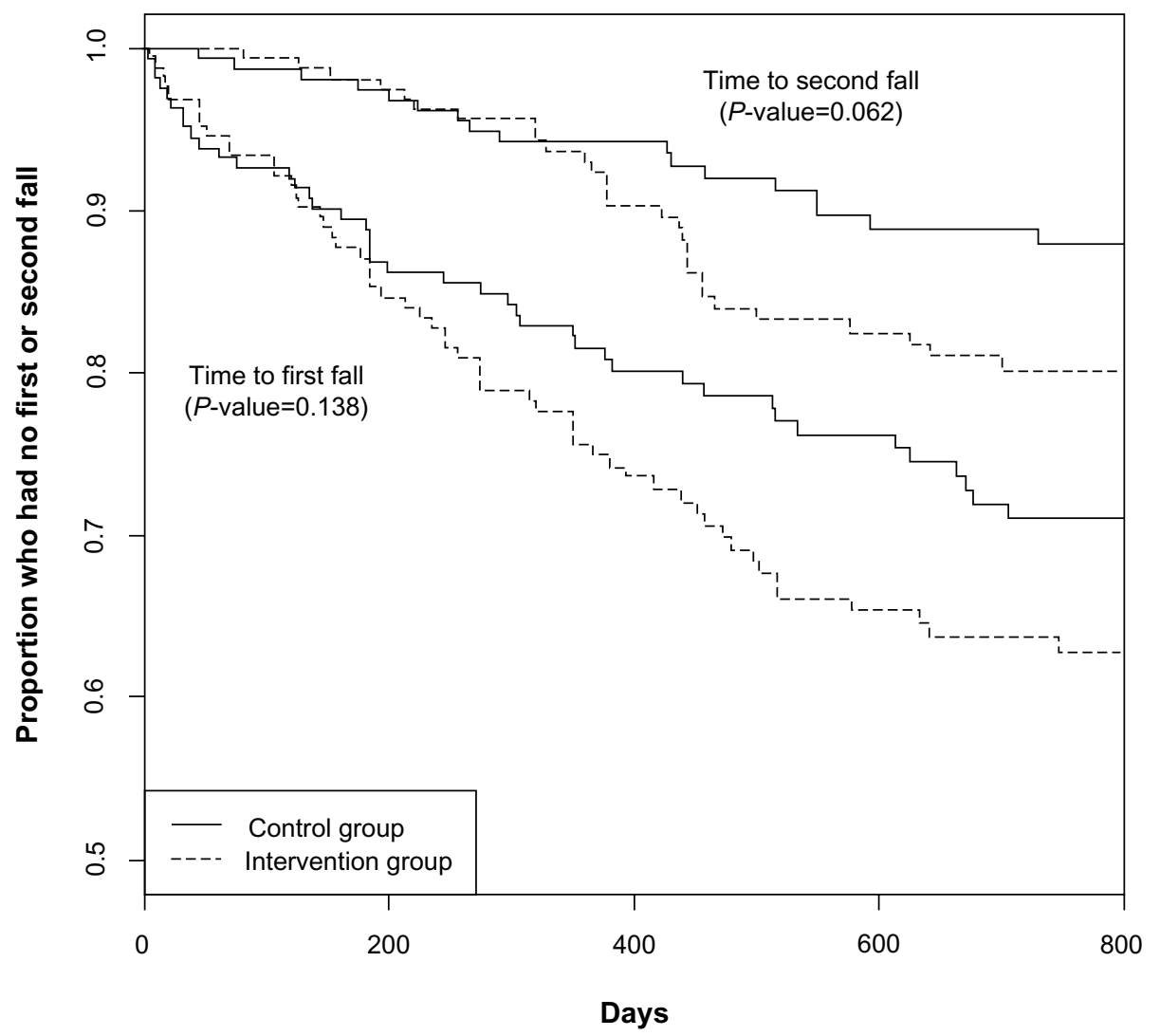

Figure 2 Comparison of Kaplan-Meier survival curves for time to first and second fall between control and intervention group over 2 years of follow-up. 
Table 2 Cox models for time to first fall and for recurrent falls (control or intervention group)*

\begin{tabular}{|c|c|c|c|c|c|c|}
\hline & \multicolumn{3}{|l|}{ First fall } & \multicolumn{3}{|l|}{ Recurrent falls } \\
\hline & Model I & Model $2^{\dagger}$ & Model $3^{\dagger}$ & Model I & Model $2^{\dagger}$ & Model $3^{\dagger}$ \\
\hline Intervention group & $1.35(0.91-2.02)$ & $\mathrm{I} .4 \mathrm{I}(0.94-2.10)$ & $1.40(0.93-2.10)$ & $1.42(1.00-2.02)$ & $1.46(1.03-2.08)$ & $1.46(1.03-2.09)$ \\
\hline Previous falls & - & - & $1.24(0.81-1.90)$ & - & - & $1.09(0.74-1.60)$ \\
\hline Disability $\ddagger$ & - & $1.53(1.01-2.33)$ & $1.41(0.90-2.19)$ & - & $1.48(1.02-2.13)$ & $1.44(0.97-2.12)$ \\
\hline Female & - & - & $1.27(0.82-1.98)$ & - & - & $1.18(0.80-1.75)$ \\
\hline Cognitive impairment ${ }^{\S}$ & - & - & $1.16(0.74-1.82)$ & - & - & $1.08(0.72-1.60)$ \\
\hline Comorbidity" & - & - & $0.96(0.58-1.6 \mathrm{I})$ & - & - & $0.86(0.54-1.38)$ \\
\hline
\end{tabular}

Notes: *Data are presented as the hazard ratio and corresponding $95 \%$ confidence interval; †adjusted by listed variable; ${ }^{\ddagger}$ disability, indicated by a Barthel Index $<90 ;{ }^{8}$ cognitive impairment, indicated by Spanish version of the Mini-Mental State Examination <24/35; "comorbidity, measured by the Charlson Comorbidity Index (0-37).

explanation for the lack of effect could be a paradoxical rather than undesirable effect of increased physical activity. The higher physical therapy adherence during the second year $(90 \%)$ versus the first year $(74 \%)$ resulted in an increased time at risk and therefore a higher risk of falls and injuries (fractures). Another reason for this effect could be low adherence with the home safety assessment (54\% adherence), ie, a systematic approach to identify home hazards as an important component of the intervention, including stairs in the home and lighting factors. ${ }^{35-37}$ This might be supported by the proportion of home hazards at baseline, which was found to be higher in the intervention group than in the control group. Moreover, there was poor adherence with hospital-based physical therapy and nutritional interventions in the current study, despite Spain having a system of universal health insurance such that the population has free access to these facilities (without additional cost for transport or specialist consultation). This suggests that, at the age of 85 years, more targeted physical therapy is needed as well as better integration of the different health care professionals (specialists, transport services, caregivers), especially if hospital-service specialists are used.

The second explanation is a differential in the quality of falls reporting. There is more opportunity for recording a fall in people visited more frequently (ie, our intervention group), which minimizes loss of data due to minor memory deficits in these oldest-old people. ${ }^{14}$ Therefore, "nonclassical" methods (including house alarm systems and effective telephone systems that provide health care 24 hours a day all year round) should be used in this oldest group, in addition to monthly calendars and telephone calls to report falls and gain a clearer picture of what happened with our elders.

The third reason could be the contamination effect of the control group. Some of the health professionals at the centers involved in the trial had patients from both the intervention and control groups in their practices. ${ }^{38}$ Due to the study design, they did not know the group allocation of their patients. Therefore, an increase in the design of $20 \%$ of participants ${ }^{20}$ could compensate for contamination between groups to had a negligible effect in this study.

The fourth reason is that the remaining total cohort that remanded to follow-up was a healthy group of individuals (with a Barthel Index score of 95, a Charlson Comorbidity Index score of 1, and on a mean of six medications), and most (73.2\%) had not fallen in the year prior to the start of the study. Therefore, given that this group may not have had a very high falls risk, the effects of the intervention may have been diluted by this subgroup of robust patients. However, fear of falling was not reported in this trial, ${ }^{39}$ and those people who had reported multiple previous falls at recruitment (1.8\% in control group, $4.3 \%$ in the intervention group) were more likely to have experienced this problem,

Table 3 Analyses of secondary outcomes, with mean and $95 \%$ confidence interval for groups at 24 months' follow-up and mean difference between groups. Sample is shown for the complete follow-up period

\begin{tabular}{|c|c|c|c|}
\hline & \multicolumn{2}{|l|}{ Mean $(95 \% \mathrm{Cl})$} & \multirow[t]{2}{*}{ Mean difference $^{a}(95 \% \mathrm{Cl})$} \\
\hline & $\begin{array}{l}\text { Control } \\
(n=98)\end{array}$ & $\begin{array}{l}\text { Intervention } \\
(n=127)\end{array}$ & \\
\hline Fractures & $0.02(-0.18 ; 0.22)$ & $0.06(-0.13 ; 0.25)$ & $-0.03(-0.09 ;-0.02)$ \\
\hline Hospital emergencies & $0.46(0.2 \mathrm{I} ; 0.7 \mathrm{I})$ & $0.47(0.25 ; 0.69)$ & $-0.01(-0.24 ; 0.21)$ \\
\hline Hospital admissions & $0.16(-0.07 ; 0.39)$ & $0.19(0.01 ; 0.37)$ & $-0.03(-0.15 ; 0.10)$ \\
\hline Home care* & $0.19(0.12 ; 0.29)$ & $0.20(0.14 ; 0.29)$ & $-0.01(-0.13 ; 0.10)$ \\
\hline
\end{tabular}

Notes: *Proportion results; ${ }^{a}$ mean difference between the control and intervention group is estimated; negative mean differences indicate a decline in the outcome measure. Abbreviation: $\mathrm{Cl}$, confidence interval. 
Table 4 Incidence rate (95\% confidence interval) of falls and follow-up durations

\begin{tabular}{|c|c|c|c|c|}
\hline Follow-up & Control & Intervention & P-value* & Incidence rate ${ }^{* *}$ \\
\hline \multicolumn{5}{|l|}{12 months } \\
\hline Subjects, $n$ & $|3|$ & 142 & 0.56 & $0.85(0.51-1.40)$ \\
\hline 0 falls, $n(\%)$ & $98(74.8 \%)$ & $102(7 \mid .8 \%)$ & & \\
\hline I fall, $n(\%)$ & $20(15.3 \%)$ & $29(20.4 \%)$ & & \\
\hline 2 falls, $n$ (\%) & $5(3.82 \%)$ & $6(4.23 \%)$ & & \\
\hline$\geq 3$ falls, $n(\%)$ & $8(6.11 \%)$ & 5 (3.52\%) & & \\
\hline \multicolumn{5}{|l|}{ I2-24 months } \\
\hline Subjects, $n$ & 98 & 127 & 0.08 & $2.06(1.22-3.5)$ \\
\hline 0 falls, n (\%) & 7I (72.4\%) & $8 \mathrm{I}(63.8 \%)$ & & \\
\hline I fall, n (\%) & $2 \mathrm{I}(2 \mathrm{I} .4 \%)$ & $23(18.1 \%)$ & & \\
\hline 2 falls, $n(\%)$ & $3(3.06 \%)$ & $13(10.2 \%)$ & & \\
\hline$\geq 3$ falls, $n(\%)$ & $3(3.06 \%)$ & $10(7.87 \%)$ & & \\
\hline
\end{tabular}

Notes: *Chi-square test between control and intervention group for number of falls; **negative binomial model adjusted by control and intervention group variable; reference category is control group.

so this excess of $2.4 \%$ (four participants) in the intervention population with the highest number of previous falls might thus have had a small increasing effect on the mean fall risk and number of falls.

The fifth explanation is that the capacity of the national health care system may have influenced the results, as happens in other health care systems. ${ }^{17,40}$ The relatively long time interval between the initial recommendations and completion of the program may have been due to the fact that referrals to medical specialists have to be made via general practitioners. Shortening this period would be difficult without deviating from routine procedures. Further, continuous endorsement by the therapist of the need for active management of risk factors for falls was essential to actively engage participants and their families, as was shown by the increased adherence in the second year. In the second year, adherence increased for all types of recommendations (from $41 \%$ to $80 \%$ for those made by the ophthalmologist, and from $32 \%$ to $42 \%$ for those made by the audiologist) probably because of difficulties in accessing the recommended measures (such as hearing aids which are expensive and not covered by national health insurance). These findings support the notion that greater integration of health care services may be required to assess, treat, and support the elderly. ${ }^{41}$

The sixth issue is that when we analyzed for the presence of disability ${ }^{35}$ and cognitive impairment ${ }^{42,43}$ in this study, there was no difference in time to falling between the intervention or control groups. Therefore, minor baseline functional impairment (Barthel Index <90) did not impair effective self-management of risk in everyday life situations in either the control group or the intervention group. This pattern is in accordance with previous studies that have reported a nonlinear U-shaped relationship between activity levels and risk of falls, whereby people with the lowest and highest activity levels are at greater risk. ${ }^{39}$

Table 5 Adherence to recommendations in the intervention group in the first and second year

\begin{tabular}{|c|c|c|c|c|}
\hline \multirow[t]{2}{*}{ Type of recommendation } & \multicolumn{2}{|l|}{$\begin{array}{l}\text { One year } \\
(n=\mid 50)\end{array}$} & \multicolumn{2}{|l|}{$\begin{array}{l}\text { Two years } \\
(n=136)\end{array}$} \\
\hline & $\begin{array}{l}\text { Recommended } \\
\text { n (\%) }\end{array}$ & $\begin{array}{l}\text { Adhered } \\
\text { n (\%) }\end{array}$ & $\begin{array}{l}\text { Recommended } \\
\text { n (\%) }\end{array}$ & $\begin{array}{l}\text { Adhered } \\
\text { n (\%) }\end{array}$ \\
\hline Discuss medication with primary care physician & $97(65)$ & $63(65)$ & $102(75)$ & $92(90)$ \\
\hline See ophthalmologist & $88(59)$ & $36(4 I)$ & $94(69)$ & $75(80)$ \\
\hline See audiologist & $59(39)$ & $19(32)$ & $45(33)$ & $19(42)$ \\
\hline See community dietician & $135(90)$ & $104(77)$ & $109(80)$ & $97(89)$ \\
\hline See community physical therapist & $128(85)$ & $95(74)$ & $88(65)$ & $79(90)$ \\
\hline See community occupational therapist & $25(17)$ & $13(52)$ & $39(29)$ & $33(85)$ \\
\hline See neurologist & $34(23)$ & $19(56)$ & $35(26)$ & $29(83)$ \\
\hline Environmental modifications & $79(53)$ & $43(54)$ & $85(63)$ & $65(77)$ \\
\hline See social services & $66(44)$ & $33(50)$ & $55(40)$ & $33(60)$ \\
\hline Referred to hospital dietician service & & & $47(35)$ & $19(40)$ \\
\hline Referred to hospital rehabilitation service & & & $59(43)$ & $30(5 \mathrm{I})$ \\
\hline
\end{tabular}


Similarly, cognitive impairment did not have any effect on the number of falls recorded in this study, as reported elsewhere. ${ }^{39,44}$ However, other intervention programs have described lower rates of falls in older people with various degrees of cognitive impairment ${ }^{45,46}$ and efficacious programs programs in people with a caregiver and minor cognitive impairment (Mini-Mental State Examination <28). ${ }^{23}$

The major strengths of this study are the external generalizability and applicability of the results due to inclusion of all oldest-old residents of similar age registered in the national health care system in one area, regardless of their somatic and cognitive comorbidities. However, this strength might also represent a weakness in that it limits the generalizability of the findings of this study to other populations. Another major strength is the length of follow-up, given that many studies of fall prevention are limited to short periods of follow-up. The main limitation concerns the recording of falls. In an attempt to reduce memory bias, falls were confirmed by a caregiver when available or by medical records. As in other similar studies, a further limitation was the high number of study participants who were lost to follow-up; however, this resulted in a study sample size that was similar to the median population size in other fall prevention trials. ${ }^{2}$

We conclude that this multifactorial intervention to reduce falls among octogenarians, including those with cognitive impairment or comorbidities, did not lead to a decrease in the risk of falling. Further studies including new physical therapy training protocols, programs to implement new strategies for reporting falls, and increased assessment of falls risk in the oldest-old age group are needed.

\section{Acknowledgments}

This paper is published on behalf of the OCTABAIX Study Group. Members of this group include J Almeda (Unitat de Suport a la Recerca de Costa de Ponent, IDIAP J Gol) who provided statistical support, and C Fernández (CAP Rambla), A Gil (ABS Sant Andreu de la Barca), C Llopart (ABS Sant Andreu de la Barca), MJ Megido (ABS Just Oliveras), G Padrós (Laboratori Clínic L'Hospitalet), M Sarró (CAP Florida Nord), and A Tobella (ABS Martorell Rural) who assisted with data collection. This work was supported by the Fondo de Investigación Sanitaria - Instituto de Salud Carlos III, Spain (grant PS09/00552).

\section{Author contributions}

$\mathrm{AF}$ and FF conceived and designed the study and helped with preparation of the manuscript, HS provided statistical support and drafted the manuscript, TB helped with data collection and reviewed the manuscript, and OJdV and RP made critical revisions to the manuscript. All the authors made substantial contributions toward the interpretation of data and drafting of the article and agree to be accountable for all aspects of the work.

\section{Disclosure}

The authors report no financial or any other type of personal conflict of interest in this work.

\section{References}

1. Christensen K, Doblhammer G, Rau R, Vaupel JW. Ageing populations: the challenges ahead. Lancet. 2009;374:1196-1208.

2. Cameron ID, Murray GR, Gillespie LD, et al. Interventions for preventing falls in older people in nursing care facilities and hospitals. Cochrane Database Syst Rev. 2010;20:CD005465

3. Formiga F, Ferrer A, Duaso E, Olmedo C, Pujol R. Falls in nonagenarians living in their own homes: the Nonasantfeliu study. J Nutr Health Aging. 2008;12:273-286.

4. Salvà A, Bolíbar I, Pera G, Arias C. Incidence and consequences of falls among elderly people living in the community. Med Clin (Barc). 2004;122:172-176.

5. Tinetti ME, Speechley M, Ginter SF. Risk factors for falls among elderly persons living in the community. N Engl J Med. 1988;319: 1701-1707.

6. Close J, Ellis M, Hooper R, Glucksman E, Jackson S, Swift C. Prevention of falls in the elderly trial (PROFET): a randomised controlled trial. Lancet. 1999;353:93-97.

7. Gillespie LD, Robertson MC, Gillespie WJ, et al. Interventions for preventing falls in older people living in the community. Cochrane Database Syst Rev. 2012;9:CD007146.

8. Michael YL, Whitlock EP, Lin JS, Fu R, O'Connor EA, Gold R; US Preventive Services Task Force. Primary care-relevant interventions to prevent falling in older adults: a systematic evidence review for the US. Ann Intern Med. 2010;153:815-825.

9. Lamb SE, Jørstad-Stein EC, Hauer K, Becker C; Prevention of Falls Network Europe and Outcomes Consensus Group. Development of a common outcome data set for fall injury prevention trials: the Prevention of Falls Network Europe consensus. J Am Geriatr Soc. 2005;53:1618-1622.

10. Clemson L, Cumming RG, Kendig H, Swann M, Heard R, Taylor K. The effectiveness of a community-based program for reducing the incidence of falls in the elderly: a randomized trial. J Am Geriatr Soc. 2004;52:1487-1494.

11. Yates SM, Dunnagan TA. Evaluating the effectiveness of a home-based fall risk reduction program for rural community-dwelling older adults. J Gerontol A Biol Sci Med Sci. 2001;56:M226-M230.

12. Shaw FE, Bond J, Richardson DA, et al. Multifactorial intervention after a fall in older people with cognitive impairment and dementia presenting to the accident and emergency department: randomised controlled trial. BMJ. 2003;326:73.

13. Cumming RG, Ivers R, Clemson L, et al. Improving vision to prevent falls in frail older people: a randomized trial. J Am Geriatr Soc. 2007;55:175-181.

14. Moyer VA; US Preventive Services Task Force. Prevention of falls in community-dwelling older adults: US Preventive Services Task Force recommendation statement. Ann Intern Med. 2012;157:197-204.

15. Milisen K, Geeraerts A, Dejaeger E; Scientific Working Party. Use of a fall prevention practice guideline for community-dwelling older persons at risk for falling: a feasibility study. Gerontology. 2009;55:169-178.

16. Tiedemann A, Lord SR, Sherrington C. The development and validation of a brief performance-based fall risk assessment tool for use in primary care. J Gerontol A Biol Sci Med Sci. 2010;65:896-903. 
17. Hendriks MR, Bleijlevens MH, van Haastregt JC, et al. Lack of effectiveness of a multidisciplinary fall-prevention program in elderly people at risk: a randomized, controlled trial. J Am Geriatr Soc. 2008;56:1390-1397.

18. Winter H, Watt K, Peel NM. Falls prevention interventions for community-dwelling older persons with cognitive impairment: a systematic review. Int Psychogeriatr. 2013;25:215-227.

19. Jordi Gol i Gurina Foundation. Octabaix Intervention Study. Available from: http://clinicaltrials.gov/show/NCT01141166. NLM identifier: NCT01141166. Accessed January 10, 2014.

20. Ferrer A, Badia T, Formiga F, et al; Grupo de Estudio OCTABAIX. [A randomized clinical trial of falls and malnutrition prevention in community-dwelling elders aged 85 years old. The OCTABAIX study]. Rev Esp Geriatr Gerontol. 2010;45:79-85. Spanish.

21. Mahoney FI, Barthel DW. Functional evaluation: the Barthel Index. A simple index of independence useful in scoring improvement in the rehabilitation of the chronically ill. Md State Med J. 1965; 14:61-65.

22. Tinetti ME. Performance-oriented assessment of mobility problems in elderly patients. J Am Geriatr Soc. 1986;34:119-1126.

23. Lobo A, Saz P, Marcos G, et al. [Revalidation and standardization of the cognition mini-exam (first Spanish version of the Mini-Mental Status Examination) in the general geriatric population]. Med Clin (Barc). 1999;112:767-774. Spanish.

24. Guigoz Y, Vellas B, Garry PJ. Assessing the nutritional status of the elderly: the Mini Nutritional Assessment as part of the geriatric evaluation. Nutr Rev. 1996;54 Suppl:59-65.

25. Charlson ME, Pompei P, Ales KL, MacKenzie CR. A new method of classifying prognostic comorbidity in longitudinal studies: development and validation. J Chronic Dis. 1987;40:373-383.

26. Pérula LA, Varas-Fabra F, Rodríguez V, et al; EPICA Study Collaborative Group. Effectiveness of a multifactorial intervention program to reduce fall incidence among community-living older adults: a randomized controlled trial. Arch Phys Med Rehabil. 2012;10:1677-1684.

27. Hüger D, Zieschang T, Schwenk M, Oster P, Becker C, Hauer K. Designing studies on the effectiveness of physical training in patients with cognitive impairment. Z Gerontol Geriatr. 2009;42:11-19.

28. Sherrington C, Whitney JC, Lord SR, Herbert RD, Cumming RG, Close JC. Effective exercise for the prevention of falls: a systematic review and meta-analysis. J Am Geriatr Soc. 2008;56:2234-2243.

29. Petridou ET, Manti EG, Ntinapogias AG, Negri E, Szczerbinska K. What works better for community-dwelling older people at risk to fall? A meta-analysis of multifactorial versus physical exercise-alone interventions. J Aging Health. 2009;21:713-729.

30. Province MA, Hadley EC, Hornbrook MC, et al. The effects of exercise on falls in elderly patients. A preplanned meta-analysis of the FICSIT Trials. Frailty and Injuries: Cooperative Studies of Intervention Techniques. JAMA. 1995;273:1341-1347.

31. de Vries OJ, Peeters GM, Elders PJ, et al. Multifactorial intervention to reduce falls in older people at high risk of recurrent falls: a randomized controlled trial. Arch Intern Med. 2010;170:1110-1117.
32. Gill TM, Baker DI, Gottschalk M, Peduzzi PN, Allore H, Byers A. A program to prevent functional decline in physically frail, elderly persons who live at home. $N$ Engl J Med. 2002;347:1068-1074.

33. Mahoney JE, Shea TA, Przybelski R, et al. Kenosha County falls prevention study: a randomized, controlled trial of an intermediate-intensity, community-based multifactorial falls intervention. J Am Geriatr Soc. 2007;55:489-498

34. Faber MJ, Bosscher RJ, Chin A, Paw MJ, van Wieringen PC. Effects of exercise programs on falls and mobility in frail and pre-frail older adults: a multicenter randomized controlled trial. Arch Phys Med Rehabil. 2006;87:885-896.

35. Campbell AJ, Robertson MC, La Grow SJ, et al. Randomised controlled trial of prevention of falls in people aged $>$ or $=75$ with severe visual impairment: the VIP trial. BMJ. 2005;331:817.

36. Chang JT, Morton SC, Rubenstein LZ, et al. Interventions for the prevention of falls in older adults: systematic review and meta-analysis of randomised clinical trials. BMJ. 2004;328:680.

37. Hanford N, Figueiro M. Light therapy and Alzheimer's disease and related dementia: past, present, and future. J Alzheimer's Dis. 2013;33:913-922.

38. Myunghan $\mathrm{C}$, Melvin $\mathrm{H}$. Intervention programs in preventing falls: a systematic review of recent 10 years and meta-analysis. $J$ Am Med Dir Assoc. 2012;13:188. e13-e21.

39. Delbaere K, Crombez G, Vanderstraeten G, Willems T, Cambier D. Fearrelated avoidance of activities, falls and physical frailty. A prospective community-based cohort study. Age Ageing. 2004;33:368-373.

40. Gates S, Smith LA, Fisher JD, Lamb SE. Systematic review of accuracy of screening instruments for predicting fall risk among independently living older adults. J Rehabil Res Dev. 2008;45:1105-1116.

41. Spice CL, Morotti W, George S, et al. The Winchester Falls Project: a randomized controlled trial of secondary prevention of falls in older people. Age Ageing. 2009;38:33-40.

42. Härlein J, Dassen T, Halfens RJ, Heinze C. Fall risk factors in older people with dementia or cognitive impairment: a systematic review. J Adv Nurs. 2009;65:922-933.

43. Hauer K, Becker C, Lindemann U, Beyer N. Effectiveness of physical training on motor performance and fall prevention in cognitively impaired older persons: a systematic review. Am J Phys Med Rehabil. 2006;85:847-857.

44. Ploeg J, Brazil K, Hutchison B, et al. Effect of preventive primary care outreach on health related quality of life among older adults at risk of functional decline: randomised controlled trial. BMJ. 2010;340:c1480.

45. Halvarsson A, Franzén E, Farén E, Olsson E, Oddsson L, Ståhle A. Long-term effects of new progressive group balance training for elderly people with increased risk of falling - a randomized controlled trial. Clin Rehabil. 2013;27:450-458.

46. Mendes da Costa E, Pepersack T, Godin I, Bantuelle M, Petit B, Levêque A. Fear of falling and associated activity restriction in older people. Results of a cross-sectional study conducted in a Belgian town. Arch Public Health. 2012;70:1. 


\section{Supplementary Material}

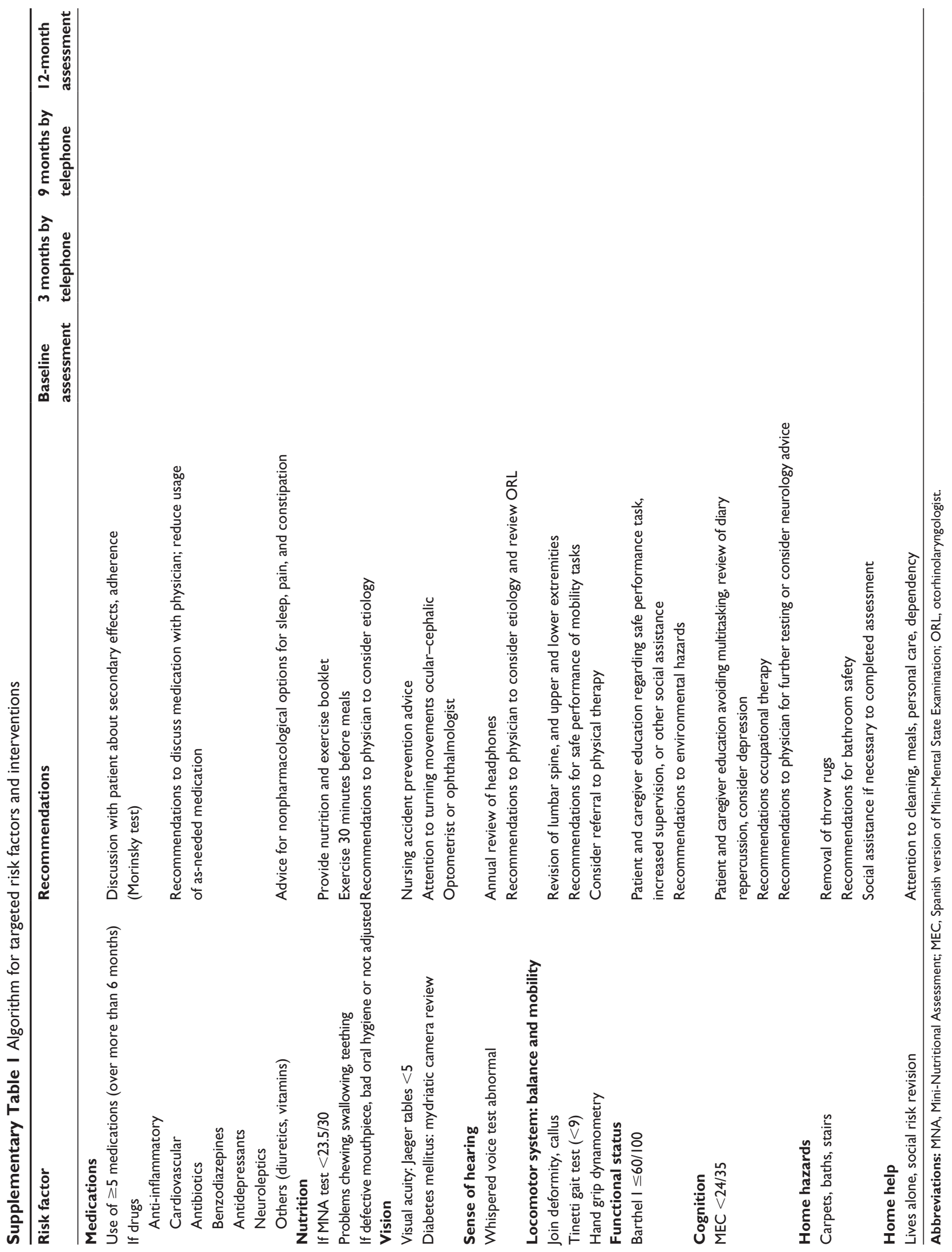




\section{Publish your work in this journal}

Clinical Interventions in Aging is an international, peer-reviewed journal focusing on evidence-based reports on the value or lack thereof of treatments intended to prevent or delay the onset of maladaptive correlates of aging in human beings. This journal is indexed on PubMed Central, MedLine, the American Chemical Society's 'Chemical Abstracts

Service' (CAS), Scopus and the Elsevier Bibliographic databases. The manuscript management system is completely online and includes a very quick and fair peer-review system, which is all easy to use. Visit $\mathrm{http}: / /$ www.dovepress.com/testimonials.php to read real quotes from published authors.

Submit your manuscript here: http://www.dovepress.com/clinical-interventions-in-aging-journal 